\title{
Correlation between serum IL-6 level and Th17/Treg ratio with Systemic Lupus Erythematosus Disease Activity
}

\author{
Adidia Carina Familia ${ }^{1}$, Yuliasih Yuliasih ${ }^{2 *}$, Lita Diah Rahmawati² \\ ${ }^{1}$ Department of Internal Medicine, Faculty of Medicine Universitas Airlangga, Surabaya, Indonesia - Dr. Soetomo General \\ Hospital Surabaya, Indonesia \\ ${ }^{2}$ Rheumatology Division, Department of Internal Medicine, Faculty of Medicine Universitas Airlangga, Surabaya, \\ Indonesia - Dr. Soetomo General Hospital Surabaya, Indonesia
}

\section{A R T I C L E I N F O}

\section{Article history:}

Received 24 October 2019

Received in revised form 25

October 2019

Accepted 29 October 2019

Available online 31 October 2019

Keywords:

Systemic lupus erythematosus, IL-6,

Th17/Treg ratio,

Autoimmune.

*) Corresponding author: yuli77@yahoo.com

\begin{abstract}
A B S T R A C T
Introduction: SLE pathophysiology shifted to a new paradigm which emphasizing the imbalance between Th17 and Treg. IL- 6 is the main cytokine believed as the regulator of the balance between Th17-Treg which play a big part in SLE pathophysiology and disease activity. This study is aim to determining the correlation between serum IL-6 level and Th17/Treg ratio with SLE disease activity on SLE inpatients.

Methods: This cross sectional study included newly diagnosed SLE patients based on American College of Rheumatology (ACR) 1997 revised criteria and confirmed by rheumatologist. All subjects underwent the same examination and assessment, SLE disease activity was scored according to SLAM score, serum IL-6 level measured using ELISA, and Th17/Treg ratio where the expression Th17-Treg detected by flowcytometry method.

Results: Thirty female subjects with active SLE had mean age 31,3 $\square$ 10,46 years. The most frequent clinical manifestations were hematologic disorders and arthritis. Serum IL-6 level was significantly elevated in SLE patients compare to healthy subjects $(200,61 \mathrm{pg} / \mathrm{ml}$ versus 45,9 pg/ $\mathrm{ml}, \mathrm{p}=0,028)$. Th17/Treg ratio were also significantly higher in SLE patients compared to healthy subjects $(2,49$ versus $1,20, p=0,31)$. Th17/Treg ratio significantly correlated with SLE disease activity $(r=0,988 ; p<0,05)$. There were no significant correlation between serum IL-6 level with Th17/Treg ratio $(r=-0,095 ; p>0,05)$ or even SLE disease activity $(r=0,066 ; p>0,05)$.

Conclusion: Serum IL-6 level had no significant correlation with Th17/Treg ratio or SLE disease activity. We found significant correlation between Th17/Treg ratio with SLE disease activity.
\end{abstract}

\section{Introduction}

Systemic lupus erythematosus (SLE) is a diverse inflammatory chronic autoimmune disorder which characterized by the participation of multiple-organ systems with varying clinical exacerbations and also remissions. ${ }^{1}$ The morbidity and mortality rate of SLE patients is still quite high with almost 5 times higher than normal population. ${ }^{2}$ SLE pathophysiology is characterized by the involvement of dysfunction of B cells, $\mathrm{T}$ cells, dendritic cells (DC), skewed cytokine production, abnormality of immunological tolerance, and the production of antinuclear autoantibodies. ${ }^{3}$

SLE was classically thought to be a B cells driven disease because of the breakdown of immunological tolerance is believed to be one of the main mechanisms which triggers the production of autoantibodies by B cells. Current evidences have demonstrated that T cell is actually fundamental in SLE pathogenesis. T cell enhance the production of autoantibodies by contributing important help to B cells through stimulating differentiation, proliferation, and maturation of $\mathrm{B}$ cells. It also supports on class-switching of autoantibodies which B cells are expressing. Therefore, by directing molecules expressed on $\mathrm{T}$ cells and their signaling pathways can be one of the highly potential therapeutic strategies in SLE. ${ }^{4,5}$

More recently, SLE has been associated to an imbalance between Th17 and regulatory T-cells (Tregs) cells which shift towards the pro-inflammatory Th17 side. Th17 are an effector T-cell subset described to promote inflammation by acting as antagonists for Treg. Tregs are crucial for the maintenance of peripheral immune tolerance. ${ }^{6}$ This disequilibrium were found in active lupus patient and correlated with clinical disease 
activity as well as organ involvement.

IL-6 is a pleiotropic cytokine involved in the physiology of almost every organ system. Current studies have showed that IL- 6 has a very important role as a regulator of the balance between Th17 cells and Treg. ${ }^{8}$ IL-6 initiates the differentiation of Th17 cells jointly with TGF- $\beta$, while it inhibits differentiation process of Treg. In particular, IL-6 trans-signaling appears to stimulate the maintenance of Th17 in inflamed tissues and regulates acute inflammation in vivo. Consequently, IL-6 promotes a proinflammatory milieu in which inducible Treg responses are suppressed. ${ }^{9}$ The aim of this study was to determining the correlation between serum IL-6 level and Th17/Treg ratio with SLE disease activity in SLE inpatients at Dr. Soetomo General Hospital, Surabaya.

\section{Methods}

This was an analytic observational study using crosssectional design. The study was conducted at the Department of Internal Medicine Dr. Soetomo General Hospital Surabaya from March to June 2017. The population studied was all hospitalized SLE patients in the Department of Internal Medicine Dr. Soetomo General Hospital Surabaya. The sample studied was all newly diagnosed SLE patients taken with consecutive sampling.

The inclusion criteria for this study were newly diagnosed SLE patients based on American College of Rheumatology (ACR) 1997 revised criteria (minimum 4 criteria from 11), aged 16-60 years, and subjects agreed to participate in the study. The exclusion criteria in this study were subjects who took any steroid or immunosuppressant medicine, had infection, malignancy, had history of smoking, asthma, acute coronary syndrome, tuberculosis, HIV/AIDS, overlapping syndrome. This study has been approved by Ethical Committee in Health Research Dr. Soetomo General Hospital Surabaya. Patients were informed the usage of their blood sample and given their consent.

All subjects underwent the same examination and assessment. Medical records were reviewed and complete laboratory data were collected. SLE disease activity was assessed by calculating the Systemic Lupus Activity Measure (SLAM) score involving lupus impairments, like constitutional, musculoskeletal, neuromotor, ocular, cardiovascular, pulmonary, gastrointestinal, reticuloendothelial, and mucocutaneous. Renal involvement is evaluated into SLAM score related to urinary sediment and serum creatinine.

\section{Stimulation process of the cells}

This examination was performed to all subjects by the Clinical Pathology Laboratory Dr. Soetomo General Hospital Surabaya. Stimulation of normal PBMC in media for about 5 hours with PMA/Ionomycin (at $50 \mathrm{ng} /$ $\mathrm{ml}$ and $1 \mu \mathrm{g} / \mathrm{ml}$ respectively for every 1 million cells) in the presence of BD GolgiStop ${ }^{\mathrm{TM}}$ Protein Transport Inhibitor (554724, BD Pharmingen). Add $4 \mu \mathrm{l}$ of BD GolgiStop $^{\mathrm{TM}}$ for every $6 \mathrm{ml}$ of cell culture and mix thoroughly.

\section{Flow cytometry analysis}

Measure Th17 and Treg percentages using Human Th17/Treg Phenotyping Kit(BD Biosciences, 560762, 51-9006636). Both of cells collected from PBMC of the SLE patients and healthy subjects. Afterward, cells were fixed and permeabilized with Human FoxP3 Fix/ Perm solution, washed twice with stain buffer, then stain with cocktail of PE anti-human IL-17A, PerCP. cy5-5 anti-human CD4 antibody, Alexa Fluor 647 antihuman FoxP3 antibody for 40 minutes in the dark. Flow cytometry was performed using BD FACSCaliburTM System (BD Biosciences) and analyzed using BD CellQuestTM Pro Software (BD Biosciences). Th17 were cells which expressed CD4+ IL-17+ and Treg were cells which expressed CD4+ FoxP3+.

\section{Serum Level Assay of IL-6}

This examination was performed to all subjects by the Clinical Pathology Laboratory Dr. Soetomo General Hospital Surabaya. Fresh blood from each subjects collected in serum separator tube was centrifuged for $15 \mathrm{~min}$ at $1000 \times \mathrm{g}$ at $2-8^{\circ} \mathrm{C}$. The supernatant was collected into fresh tubes and stored in $-70^{\circ} \mathrm{C}$ until the next process for enzyme-linked immunosorbent assay (ELISA). IL-6 was quantitatively detected by Human ELISA kit in duplicate for each subject according to the manufacturer's procedure (Elabscience, catalog. E-EL-H0102).

\section{Statistical analysis}

All collected data was arranged in tabular form and processed statistically using SPSS version 23.0 (IBM, New York). Normality of the data was analyzed by Kolmogorov-Smirnov test. The correlation between IL-6 level and Th17/Treg ratio with disease activity was analyzed using pathway analysis using Lisrel program. Then, each of the variables reanalyzed using Pearson correlation test (when the data was not normally distributed) or the correlation test of Spearman (when the data was abnormally distributed) for confirmation. $\mathrm{P}<0,05$ was considered significant. The strength of the relationship was based on the correlation coefficient.

\section{Results}

Overall this study obtained 30 females patients who met the inclusion-exclusion criteria and 3 additional healthy subjects with no history of autoimmune diseases. The mean of SLE patients age was 31,3 $\square$ 10,46 years old. The clinical information and laboratory examination of SLE patients is shown in Table 1. Most of the clinical manifestations were hematologic abnormality (lymphopenia), arthritis, and serositis (Table 2).

\section{IL-6 level, Th17/Treg ratio, SLAM, Correlation between variables and other disease activity parameters}

IL-6 levels were significantly higher in SLE patients compared to healthy subjects $(200,61 \mathrm{pg} / \mathrm{ml}$ versus 45,9 $\mathrm{pg} / \mathrm{ml}, \mathrm{p}=0,028)$. Th17/Treg ratio were also significantly higher in SLE patients compared to healthy subjects $(2,49$ versus $1,20, p=0,31)$ (figure 1). Comparison of variables between SLE patients and healthy control was 
using Mann-Whitney U test. All of SLE subjects were in active condition with mean score $29,3 \pm 3,9$, vary range between 22 to 37 .

Only Th17/Treg ratio had significant strong positive correlation with SLE disease activity measured with $\operatorname{SLAM}(\mathrm{p}=0,000)$. There were no significant correlation between IL-6 level and Th17 percentage $(p=0,585)$, no significant correlation between IL-6 level and Treg percentage $(p=0,665)$, no significant correlation between IL-6 level and Th17/Treg ratio $(p=0,619)$, and also no significant correlation between IL-6 level and SLAM $(\mathrm{p}=0,066)$. Statistics analysis were using Pathway analysis and reconfirm with Spearman's correlation.

We found significant positive correlation between $\operatorname{SLAM}$ with CRP $(p=0,023), \mathrm{C} 3(\mathrm{p}=0,000), \mathrm{C} 4(\mathrm{p}=0,000)$. We also found significant positive correlation between Th17/Treg ratio with CRP $(p=0,016)$, C3 $(0,000)$, C4 $(\mathrm{p}=0,000)$. We found significant positive correlation between IL-6 level and anti ds-DNA level $(\mathrm{p}=0,040)$. Statistics analysis were using Spearman's correlation.

Table 1. Clinical information and laboratory examination for subjects in this study

\begin{tabular}{|c|c|c|c|c|}
\hline \multirow{2}{*}{ Indicator } & \multicolumn{4}{|c|}{ Total $(n=30)$} \\
\hline & n (\%) & Mean \pm SD & Minimum & Maximum \\
\hline \multicolumn{5}{|l|}{ Sex } \\
\hline Male & $0(0)$ & & & \\
\hline Female & $30(100)$ & & & \\
\hline Age (years) & & $31,3 \pm 10,46$ & 16 & 53 \\
\hline BMI (kg/m2) & & $18,88 \pm 2,42$ & 13,67 & 24,44 \\
\hline Hemoglobin (gr/dl) & & $7,13 \pm 2,32$ & 2,3 & 12,4 \\
\hline Leucocyte (cell/mm3) & & $8055,67 \pm 3442,18$ & 2200 & 17220 \\
\hline Lymphocyte (cell/mm3) & & $967,87 \pm 427,78$ & 260 & 2210 \\
\hline Thrombocyte (cell/mm3) & & $212766,67 \pm 206889,06$ & 2000 & 744000 \\
\hline ESR (mm/hour) & & $61,83 \pm 38,18$ & 2 & 130 \\
\hline CRP (mg/dl) & & $30,16 \pm 59,45$ & 0,10 & 290,77 \\
\hline $\mathrm{C} 3(\mathrm{mg} / \mathrm{dl})$ & & $28,88 \pm 12,98$ & 6,00 & 59,50 \\
\hline $\mathrm{C} 4$ (mg/dl) & & $16,95 \pm 11,72$ & 5,00 & 54,30 \\
\hline
\end{tabular}

Table 2. Clinical manifestations according ACR 1997 criteria for subjects in this study

\begin{tabular}{lcc}
\hline \multicolumn{1}{c}{ Characteristic ACR 1997 } & Total & Percentage (\%) \\
\hline Malar rash & 4 & 13,3 \\
\hline Discoid rash & 8 & 26,7 \\
\hline Photosensitivity & 13 & 43,3 \\
\hline Oral ulceration & 10 & 33,3 \\
\hline Arthritis & 23 & 76,7 \\
\hline Serositis & 14 & 46,7 \\
\hline Nephritis & 8 & 26,67 \\
\hline Neurological manifestations & 6 & 20,0 \\
\hline Hematologic manifestations & 30 & 100,0 \\
\hline Hemolytic anemia with Areticulosis & $\mathbf{4}$ & 13,3 \\
\hline Leucopenia $<4000 / m m 3$ & $\mathbf{1}$ & 3,3 \\
\hline Lymphopenia $<1500 / m m 3$ & $\mathbf{2 7}$ & 90,0 \\
\hline Thrombocytopenia $<100.000 / m m 3$ & $\mathbf{1 2}$ & 40,0 \\
\hline Anti ds-DNA positive $(>92,6$ WHO & 12 & 40,0 \\
unit/mL) & 24 & 80,0 \\
\hline ANA test positive $(\geq 20$ unit) & &
\end{tabular}



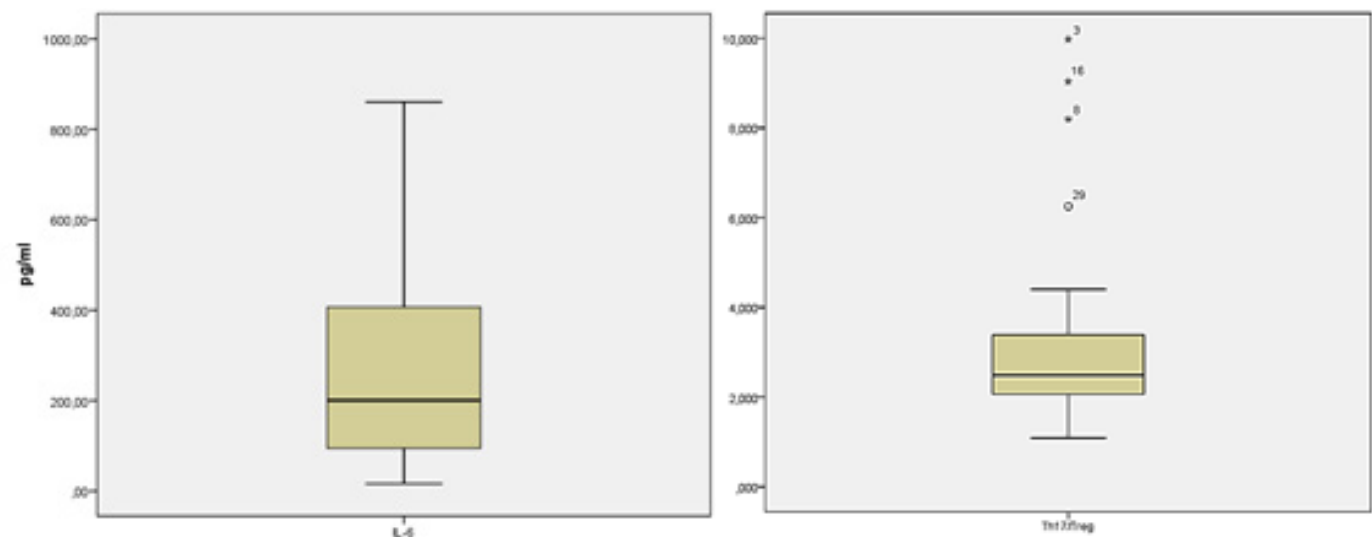

Figure 1. A. The mean of serum IL-6 level of the SLE subjects. B. The mean of Th17/Treg ratio of SLE subjects
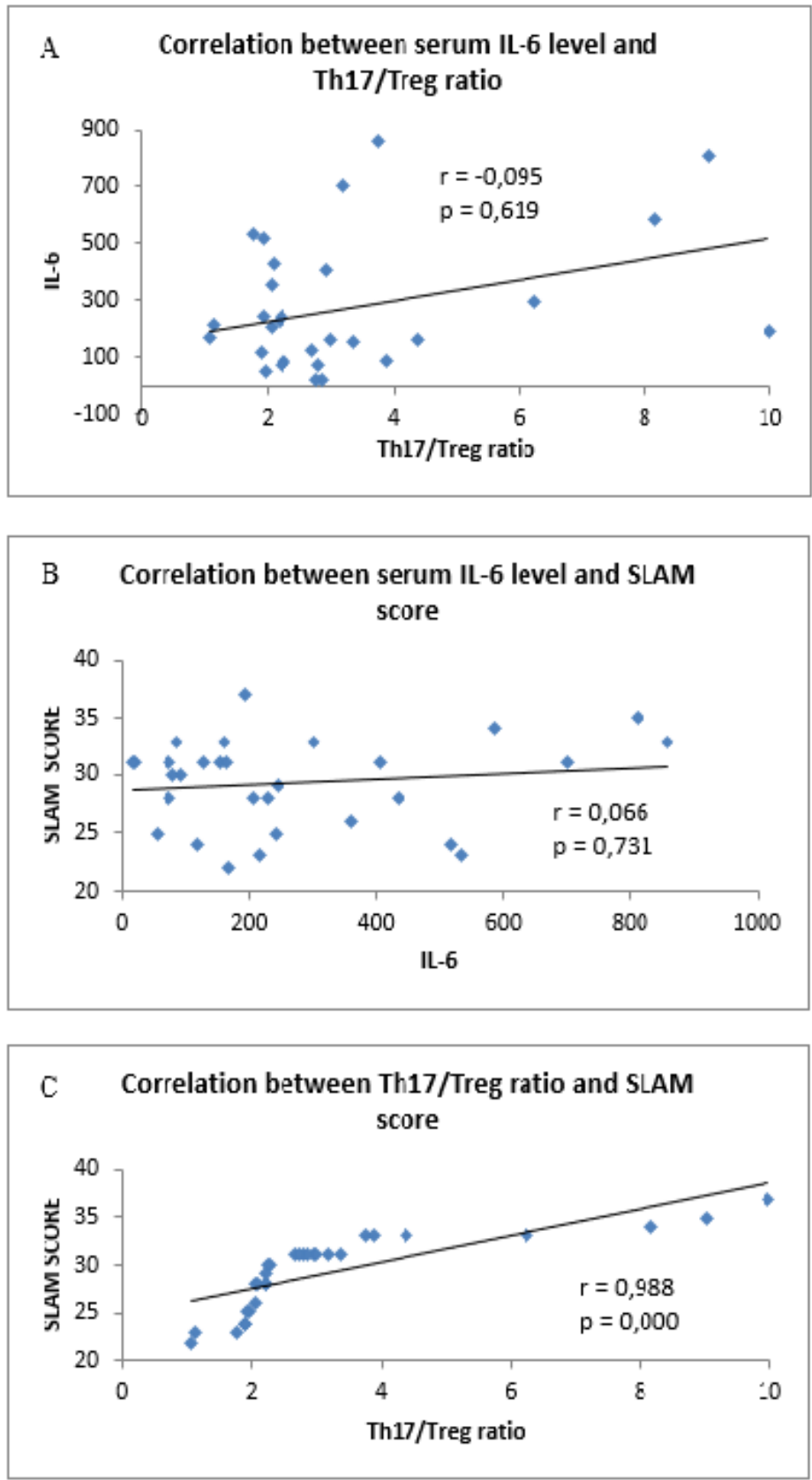

Figure 2. Correlation between serum IL-6 level, Th17/Treg ratio, and SLAM score from the SLE subjects. A. IL-6 vs Th17/Treg ratio. B. IL-6 vs SLAM. C. Th17/Treg ratio vs SLAM 


\section{Discussion}

To the best of our knowledge, this is the first work analyze correlation between serum IL-6 level and Th17/Treg ratio. We demonstrated serum IL-6 level had no significant correlation with Th17/Treg ratio or SLE disease activity and also there is significant correlation between Th17/Treg ratio with SLE disease activity.

The comparisons between women and men in each SLE study maybe vary but women are mostly suffered from SLE. In this study we obtained 30 women SLE sample. This finding accordance with similar SLE study conducted in Yogyakarta, South Korea, India, Sudan, and Egypt (10-14). SLE is more common happen in productive age accordance to our study and other similar studies. ${ }^{12-14}$ These findings related to genetic susceptibility and influence of hormone such as estrogen and prolactin which have the highest level in productive age. . $^{15,16}$

IL-6 levels were significantly greater in SLE patients compared to healthy subjects in this study. Several other studies reported the same finding about excessive IL-6 level in SLE patients compared to healthy subjects which contributed to the pathogenesis of SLE. ${ }^{17-19}$ Although we found significant escalation of IL-6 level, somehow it did not have any significant correlation with SLAM score in line with prior results. ${ }^{20-23}$ Study by Peterson et al. reported no correlation between serum and urinary IL-6 in SLE patients. Nevertheless, they analyzed that urinary IL-6 expression correlated with renal impairment and also with lupus activity evaluated by SLAM score. ${ }^{21}$ This finding supporting the concept from similar studies that assessment of local levels of IL-6 (CSF, synovial fluid) provides a more possible reliable marker of specific organ disease activity than does measurement of circulating IL-6. ${ }^{3,24}$

Our current study found no significant correlation between IL-6 level and Th17 percentage, no significant correlation between IL-6 level and Treg percentage, no significant correlation between IL-6 level and Th17/ Treg ratio, and also no significant correlation between IL-6 level and SLAM. Other study reported positive correlation between IL-6 levels and Th17 percentage, negative correlation between TGF- $\beta 1$ levels and Th17 percentage, and negative correlation between TGF- $\beta 1 /$ IL-6 ratio and Th17 percentage (17). We assume IL-6 do not have a direct strong influence to Th17-Treg. Although IL- 6 believed as main regulator of the equilibrium between Th17-Treg, we assume the role of IL- 6 in the pathogenesis SLE is still debatable. This was due to a complex milieu environment of cytokine and chemokine which affect the differentiation from CD4+ naïve T cells to CD4+ effector T cells, including TGF- $\beta$, IL-23, IL-21, IL-2, etc. However, further study needs to consider to analyzing the role of IL-6 or other cytokines in SLE pathogenesis.

Further analysis in our current study found significant positive correlation between IL-6 level and anti ds-DNA level. It was reported that IL-6 level was correlated with anti ds-DNA from other studies $(1,24)$. IL- 6 is one of the first cytokines studied in the pathogenesis of SLE due to its close connection with B lymphocytes. One of the key effect of IL-6 is to promote B lymphocyte maturation into plasma cells and enhance immunoglobulin production. ${ }^{25}$ In vitro studies where lymphoblastoid cells isolated from lupus subjects expressed heightened levels of IL-6 and immunoglobulin compared to healthy subjects. A blockade of IL- 6 will result in decrease secretion of anti-dsDNA and immunoglobulin. ${ }^{26,27}$

Only Th17/Treg ratio had significant strong positive correlation with SLE disease activity measured with SLAM. We found significant positive correlation between Th17/Treg ratio with CRP, C3, and C4. Further analysis in our study we also found significant positive correlation between SLAM with CRP, C3, and C4. SLE has been associated to an imbalance between Th17 and Treg cells which shift towards the pro-inflammatory Th17 side. Th17 are an effector T-cell subset promoting inflammation by acting as antagonists for Treg. Treg are crucial for the maintenance of peripheral immune tolerance. ${ }^{6}$ This disequilibrium in active lupus patient correlated with clinical disease activity as well as organ involvement. ${ }^{7}$ These findings accordance to other previous study which concluded Th17/Treg ratio can be used to differentiate inactive-active SLE and severity. The greater the ratio obtained then it more active disease level and severity. ${ }^{28,29}$

\section{Conclusion}

Although IL-6 level had no significant correlation with Th17/Treg ratio or SLE disease activity (SLAM score). There was significant correlation between Th17/Treg ratio with SLAM score. These findings assumes that IL-6 alone did not has direct influence to the imbalance of Th17/Treg and also SLE disease activity. IL-6 had a direct effect to B cell autoreactive, but not towards T cell. IL-6 would need other cytokine milieu to give a greater effect in $\mathrm{T}$ cell autoreactivity.

\section{Conflict of Interest}

The author stated there is no conflict of interest

\section{References}

1. Abdel Galil SM, Ezzeldin N, El-Boshy ME. The role of serum IL-17 and IL-6 as biomarkers of disease activity and predictors of remission in patients with lupus nephritis. Cytokine [Internet]. 2015 Dec;76(2):280-7. Available from: http://dx.doi.org/10.1016/j. cyto.2015.05.007

2. Kasjmir YI, Handono K, Wijaya LK, Hamijoyo L, Albar Z, Kalim $\mathrm{H}$, et al. Rekomendasi Perhimpunan Reumatologi Indonesia untuk Diagnosis dan Pengelolaan Lupus Eritematosus Sistemik [Internet]. 2011. 1-54 p. Available from: https://www.pbpapdi.org/images/ file_guidelines/14_Rekomendasi_Lupus.pdf

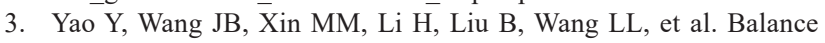
between inflammatory and regulatory cytokines in systemic lupus erythematosus. Genet Mol Res. 2016;15(2):1-8.

4. Mak, A Kow N. The Pathology of T Cells in Systemic Lupus Erythematosus. J Immunol Res. 2014;2014:1-9.

5. Moulton VR, Tsokos GC. Abnormalities of $\mathrm{T}$ cell signaling in systemic lupus erythematosus. 2011;13(2):207.

6. Fasching $\mathrm{P}$, Stradner M, Graninger W, Dejaco C, Fessler J. Therapeutic potential of targeting the Th17/Treg axis in autoimmune disorders. Molecules. 2017;22(1).

7. Wang D, Huang S, Yuan X, Liang J, Xu R, Yao G, et al. The regulation of the Treg/Th17 balance by mesenchymal stem cells in human systemic lupus erythematosus. Cell Mol Immunol. 2017;14(5):423-31.

8. Kimura A, Kishimoto T. IL-6: Regulator of Treg/Th17 balance. Eur J Immunol. 2010;40(7):1830-5.

9. Neurath MF, Finotto S. IL-6 signaling in autoimmunity, chronic inflammation and inflammation-associated cancer. Cytokine Growth Factor Rev [Internet]. 2011;22(2):83-9. Available from: http://dx.doi.org/10.1016/j.cytogfr.2011.02.003

10. Paramaiswari A, Kertia N, Achadiyono DW. Relationship Between Systemic Lupus Activity Measurement (SLAM) Score and 
Mortality in Systemic Lupus Erytemathosus (SLE) Inpatients. J Intern Med Acta Interna. 2014;4(1):15-22.

11. Chun HY, Chung JW, Kim HA, Yun JM, Jeon JY, Ye YM, et al. Cytokine IL-6 and IL-10 as biomarkers in systemic lupus erythematosus. J Clin Immunol. 2007;27(5):461-6.

12. Umare V, Pradhan V, Nadkar M, Rajadhyaksha A, Patwardhan M, Ghosh KK, et al. Effect of proinflammatory cytokines (IL-6, TNF-alpha, and IL-1beta) on clinical manifestations in Indian SLE patients. Mediat Inflamm. 2014;2014:385297.

13. Ahmed N, Shigidi M, Al Agib AN, Abdelrahman H, Taha E. Clinical features and antinuclear antibodies profile among adults with systemic lupus erythematosus and lupus nephritis: a crosssectional study. Pan Afr Med J. 2017;27:114.

14. Sabry A, Elbasyouni SR, Sheashaa HA, Alhusseini AA, Mahmoud $\mathrm{K}$, George SK, et al. Correlation between levels of TNF-alpha; and IL-6 and hematological involvement in SLE Egyptian Patients with lupus nephritis. Int Urol Nephrol. 2006;38(3-4):731-7.

15. Tsokos GC. Systemic lupus erythematosus. N Engl J Med [Internet]. 2011;365:2110-21. Available from: https://www.nejm.org/doi/ full/10.1056/NEJMra1100359

16. Treadwell EL, Wiley K, Word B, Melchior W, Tolleson WH, Gopee N, et al. Prolactin and Dehydroepiandrosterone Levels in Women with Systemic Lupus Erythematosus: The Role of the Extrapituitary Prolactin Promoter Polymorphism at -1149 G/T. J Immunol Res [Internet]. 2015;2015:1-10. Available from: http:// dx.doi.org/10.1155/2015/435658

17. Handono K, Marisa D, Kalim H, Mawarti H. The associations among serum levels of vitamin D, TGF- $\beta /$ IL- 6 balance and Treg/Th17 balance in systemic lupus erythematosus patients in Indonesia. Int J Biochem Biotechnol [Internet]. 2013;2(9):490-6. Available from: http://www.ncbi.nlm.nih.gov/pubmed/23585405

18. Galil SMA, Ezzeldin N, Said D, El-Boshy M. IL-17 is a key cytokine correlating with disease activity and clinical presentation of systemic lupus erythematosus. Indian J Rheumatol [Internet]. 2015 Dec;10(4):196-201. Available from: http://dx.doi.org/10.1016/j. injr.2015.06.003

19. Hammadi SS, Hussain M. Elevated Levels of IL- 6 in serum of SLE patients correlated with High- sensitivity CRP and ESR. Basrah J Sci. 2014;32(2):112-36
20. Gröndal G, Gunnarsson I, Rönnelid J, Rogberg S, Klareskog L, Lundberg I. Cytokine production, serum levels and disease activity in systemic lupus erythematosus. Clin Exp Rheumatol [Internet]. 2000;18:565-70. Available from: https://www.clinexprheumatol. org/article.asp? $\mathrm{a}=1671$

21. Peterson E, Robertson A, Emlen W. Urinary Interleukin-6 in Systemic Lupus Erythematosus. Lupus. 1996;5:571-5.

22. Dima A, Jurcut C, Balanescu P, Balanescu E, Badea C, Caraiola $\mathrm{S}$, et al. Clinical significance of serum and urinary interleukin-6 in systemic lupus erythematosus patients. Egypt Rheumatol [Internet]. 2017;39(1):1-6. Available from: http://dx.doi.org/10.1016/j. ejr.2016.05.005

23. Ripley BJM, Goncalves B, Isenberg DA, Latchman DS, Rahman A. Raised levels of interleukin 6 in systemic lupus erythematosus correlate with anaemia. Ann Rheum Dis. 2005;64(6):849-53.

24. Eilertsen G, Nikolaisen C, Becker-Merok A, Nossent J. Interleukin-6 promotes arthritis and joint deformation in patients with systemic lupus erythematosus. Lupus [Internet]. 2011 May 21;20(6):607-13. Available from: http://journals.sagepub.com/ doi/10.1177/0961203310392432

25. Yap DYH, Lai KN. The role of cytokines in the pathogenesis of systemic lupus erythematosus - From bench to bedside. Nephrology. 2013;18(4):243-55.

26. Linker-israeli M, Deans RJ, Wallace DJ, Prehn J, Ozeri-chen T, Klinenberg JR. Elevated levels of endogenous IL-6 in systemic lupus erythematosus. J Immunol. 1991;147(1):117-23.

27. Klashman DJ, Martin RA, Martinez-maza O, Stevens RH. In vitro regulation of $\mathrm{B}$ cell differentiation by interleukin- 6 and soluble CD23 in systemic lupus erythematosus B cell subpopulations and antigen-induced normal B cells. Arthritis Rheum. 1991;34(3):27686.

28. Ma J, Yu J, Tao X, Cai L, Wang J, Zheng SG. The imbalance between regulatory and IL-17-secreting CD4+ T cells in lupus patients. Clin Rheumatol. 2010;29(11):1251-8.

29. Yang J, Chu Y, Yang X, Gao D, Zhu L, Yang X, et al. Th17 and natural treg cell population dynamics in systemic lupus erythematosus. Arthritis Rheum. 2009;60(5):1472-83. 